\title{
Immunosuppressive and Immunomodulating Therapy for Atopic Dermatitis in Pregnancy: An Appraisal of the Literature
}

\author{
Sofine Heilskov • Mette S. Deleuran · Christian Vestergaard
}

Received: August 25, 2020 / Published online: November 2, 2020

(C) The Author(s) 2020

\section{ABSTRACT}

The aim of this appraisal of the literature is to elucidate the effects of immunosuppressive and immunomodulating agents used to treat atopic dermatitis (AD) on risk factors for fertility, pregnancy, and breastfeeding. Negative side effects of the psychological and physical stresses associated to AD flairs and uncontrolled AD are discussed, in order to evaluate the consequences of abstaining from treatment. Research on pregnancies in Danish women suggests a tendency towards an increased use of topical steroids and ultraviolet light therapy during pregnancy, compared to before conception, confirming the need for these patients to receive treatment, as well as decreased use of systemic treatments, suggesting a tendency towards undertreatment in this patient population. It is important that effective treatment be provided to pregnant women with AD. Here we present an appraisal of current knowledge on treatments for $\mathrm{AD}$ and the risks of exposure for the fetus and breastfed infant. Since little is known about the association between $\mathrm{AD}$, pregnancy, and systemic treatment, we generalize conclusions based on studies on treatments of pregnant women who have undergone organ transplantation and who have inflammatory bowel disease, rheumatic disease, and autoimmune disease. The majority of recommendations are therefore based on a low or very low quality of evidence according to the GRADE system. The selected studies reflect the authors' assessment regarding originality and importance in the context of this appraisal. It is always the treating doctor's responsibility to stay updated on current literature when treating patients, especially pregnant patients.

Keywords: Atopic dermatitis; Azathioprine; Calcineurin inhibitors; Corticosteroids; Crisaborole; Dupilumab; Methotrexate; Mycophenolate mofetil; Pregnancy; Ultraviolet light therapy 


\section{Key Summary Points}

Atopic dermatitis in pregnancy is common.

It is important to offer effective treatment to pregnant women with moderate to severe atopic dermatitis.

Optimization of treatment prior to conception and effective adjustment of treatment throughout pregnancy is important.

Systemic treatment for pregnant patients whose condition is not adequately managed with topical treatment and ultraviolet light therapy is the task of a specialist.

Initialization of therapy must take into account the costs of the treatment and the benefits to both mother and child.

\section{DIGITAL FEATURES}

This article is published with digital features to facilitate understanding of the article. To view digital features for this article go to https://doi. org/10.6084/m9.figshare.13032833.

\section{INTRODUCTION}

Atopic dermatitis (AD) is a heterogenic [1, 2] and multifactorial disease, the severity of which is influenced by genetic and immunological factors [3]. Due to its high prevalence, AD has a significant impact on quality of life and general health and is a substantial and relevant health problem worldwide [4].

The treatment of AD is well established. Firstline therapy consists of topical corticosteroids (TCS) and/or topical calcineurin inhibitors (TCI), with moisturizers always provided concomitantly to help re-establish skin barrier function. However, this therapy may not be sufficient in severe cases. Depending on the country, $44-57 \%$ of adult patients with AD have moderate disease and $12-21 \%$ have severe disease, as measured on the severity score Patient Oriented Scoring of Atopic Dermatitis (POSCORAD) [5]. In these latter two patient groups, systemic treatment with immunomodulating drugs is often needed. Approximately one-half of the $\mathrm{AD}$ population are females and $\mathrm{AD}$ affects all age groups. Therefore, some women with $\mathrm{AD}$ who desire to conceive may potentially be actively treated with an immunomodulating treatment. The use of immunomodulating drugs in this patient group is an important issue that may have consequences for both mother and child. The impact of recently licensed immunomodulating drugs on fertility, pregnancy, fetal development, and the breastfeeding child is still unclear. Consequently, the only recommendation that can currently be made is to avoid these drugs.

The purpose of this review is to appraise the literature on immunosuppressive and immunomodulating treatment regimens, topical as well as systemic, for $\mathrm{AD}$ during pregnancy. We review known fertility, pregnancy, and breastfeeding risk factors, with the aim to help doctors and patients in their decisionmaking regarding choice of treatment.

\section{METHODS}

We conducted an appraisal of the current literature on the treatment of pregnant women suffering from $\mathrm{AD}$ as well as on the use of systemic immunosuppressive and immunomodulating drugs in pregnant women suffering from other inflammatory diseases. Due to ethical considerations no comprehensive randomized studies have ever been carried out in pregnant patients. Therefore, the information presented here has been collected from registry studies, case studies, and small observational studies, and from experience with treating other diseases in pregnant women. We generalize on the conclusions drawn by authors of studies on various patient groups, including those with inflammatory bowel disease, rheumatic disease, and autoimmune diseases and transplant 
Table 1 Recommendations for immunosuppressive and immunomodulating treatment options for atopic dermatitis

\begin{tabular}{|c|c|c|c|c|}
\hline & DRUG & $\begin{array}{l}\text { PLANNING } \\
\text { PREGNANCY }\end{array}$ & PREGNANCY & BREASTFEEDING \\
\hline \multirow{4}{*}{$\begin{array}{l}\text { TOPICAL } \\
\text { TREATMENT }\end{array}$} & Corticosteroids & & & \\
\hline & Calcineurin inhibitors & & & \\
\hline & Crisaborol & & & \\
\hline & UV-therapy & & & \\
\hline \multirow{6}{*}{$\begin{array}{l}\text { SYSTEMIC } \\
\text { TREATMENT }\end{array}$} & Corticosteroids & & & \\
\hline & Cyclosporin A & & & \\
\hline & Azathioprin & & & \\
\hline & Metotrexate & & & \\
\hline & Mycophenolate mofetil & & & \\
\hline & Dupilumab & & & \\
\hline
\end{tabular}

RECOMMENDED

SPECIALIST TASK NOT RECOMMENDED
The table illustrates the authors recommendations. The table gives an overview of which treatment that can be used at; any time (GREEN), which is a specialist task ( at present can not be recommended (ORANGE) and which are contra indicated (RED), when planning pregnancy, in pregnancy and when breastfeeding a child. patients. We have chosen studies where polypharmacy is avoided, when possible. Based on this and our clinical experience, we present our recommendations for treatment options (Table1) and present the level of evidence underlying these recommendations, in accordance with the GRADE system [6] (Table 2).

This article is based on previously conducted studies and does not contain any studies with human participants or animals performed by any of the authors.

\section{THE EFFECT OF AD ON MATERNAL STRESS, QUALITY OF LIFE, AND PREGNANCY}

During pregnancy, the immune system is skewed towards a T helper 2 (Th2)-dominated immune response in order to induce tolerance to the fetus [7]. AD in itself is also a Th2-driven disease, and women with $\mathrm{AD}$ thus have an increased risk of experiencing flairs in their skin disease during pregnancy. AD is the most common skin disease in pregnancy [8] and typically flairs in the second or third trimester.
Atopic eruption of pregnancy (AEP) is a dermatitis that is clinically and histologically indistinguishable from $\mathrm{AD}$, yet it is considered to be unique to pregnancy since $80 \%$ of the patients have no prior history of skin diseases [9]. Treatment of AEP is the same as that for AD.

Contrary to the fact that AD tends to worsen during pregnancy, a registry study involving 10,441 pregnancies revealed a pattern of increased use of TCS and ultraviolet (UV) light treatment concomitant with decreased use of TCI and systemic treatments, compared to use prior to pregnancy. This trend could reflect a tendency of women to endure more AD flairups during pregnancy combined with a more cautious and restricted approach to treatment [9].

The social isolation effect of $\mathrm{AD}$ and its physiological processes on fertility have not been fully investigated. Reports of complications in pregnancy linked directly to $\mathrm{AD}$ are sparse. Staphylococcal neonatal septicemia and premature rupture of membranes are the only complications reported to date to be significantly increased in pregnant $\mathrm{AD}$ patients [9]. $\mathrm{AD}$ has a negative impact on the quality of life, and a slight change in severity has a large 
Table 2 "Grade Score" for recommended treatment approach: immunosuppressive and immunomodulating treatment options for atopic dermatitis

\begin{tabular}{|c|c|c|c|c|}
\hline & DRUG & $\begin{array}{l}\text { PLANNING } \\
\text { PREGNANCY }\end{array}$ & PREGNANCY & BREASTFEEDING \\
\hline \multirow{4}{*}{$\begin{array}{l}\text { TOPICAL } \\
\text { TREATMENT }\end{array}$} & Corticosteroids & strong & strong & strong \\
\hline & Calcineurin inhibitors & weak & weak & weak \\
\hline & Crisaborol & weak & weak & weak \\
\hline & UV-therapy & strong & strong & weak \\
\hline \multirow{6}{*}{$\begin{array}{l}\text { SYSTEMIC } \\
\text { TREATMENT }\end{array}$} & Corticosteroids & weak & weak & weak \\
\hline & Cyclosporin A & weak & weak & weak \\
\hline & Azathioprin & weak & weak & weak \\
\hline & Metotrexate & strong & \multirow{2}{*}{$\begin{array}{l}\text { strong } \\
\text { strong }\end{array}$} & strong \\
\hline & Mycophenolate mofetil & strong & & strong \\
\hline & Dupilumab & weak & weak & weak \\
\hline
\end{tabular}

I HIGH QUALITY II MODERATE QUALITY III LOW QUALITY

\begin{abstract}
The table gives a colour graded overview of the quality of existing evidence behind the treatment recommendations in Table 1, in accordance to the GRADE system. A recommendation can, be strong: when it is clear that the effect of a drug outweighs the side effects or clearly do not. It can be weak: when the effect and the side effects are closer connected or if evidence is of low quality.(Guyatt et al BMJ. 2008 Apr 26; 336(7650): 924-926. doi: 10.1136 bmi.39489.470347.AD)
\end{abstract}

impact on quality of life scores [10]. Itch, skin pain, and sleep disturbances are dominant symptoms of the disease, and it has been confirmed that there is a significantly higher rate of depression, increased use of antidepressants, and a higher rate of suicide and suicidal ideation among $\mathrm{AD}$ patients. Treatments of $\mathrm{AD}$ that reduce both the signs and symptoms also reduce depressive symptoms [11], an observation that underlines the link between $\mathrm{AD}$ and psychological stress. Whether this link holds true in pregnant $\mathrm{AD}$ patients has not been studied in detail.

Depressed mothers have increased levels of stress hormone (cortisol) in their blood, and children who are born to these women have heightened cortisol levels, showing that the fetus is not unaffected by this milieu [12]. In terms of the impact of this milieu on perinatal outcome (gestational age at delivery, intrauterine growth retardation, pre-eclampsia, Apgar score at $5 \mathrm{~min}$, and birth weight), only a weak association between stress level and perinatal outcome has been found, with birth weight being the only significant outcome affected [13].
There are studies suggesting that intrauterine exposure to maternal stress can affect brain development. For example, intrauterine exposure to heightened cortisol levels early in pregnancy has been found to be linked to lower performance in evaluations of physical, social, and psychological skills in a child 12 months postpartum. Sustained attention performance has been found to be negatively affected in adults whose mothers had a high rate of anxiety in the first half of pregnancy [14]. However, when exposure to stress occurs late in pregnancy it has a positive effect on development in terms of these same parameters [15].

\section{IMMUNOSUPPRESSIVE AND IMMOMODULATING AGENTS USED IN THE TREATMENT OF AD}

\section{Topical Treatments}

\section{Topical Corticosteroids}

Topical corticosteroids are the first-line treatment for $\mathrm{AD}$ in all patient groups, pregnant women included. 
TCS bind to a glucocorticoid receptor located in the cell cytoplasm that is then translocated to the nucleus where it increases the transcription of anti-inflammatory cytokines and inhibits the transcription of pro-inflammatory cytokines. Negative side effects can be seen when the skin is exposed to prolonged topical treatment with potent glucocorticoids, such as reduced dermal collagen synthesis and elasticity and inhibition of keratinocyte proliferation, resulting in skin atrophy. The transdermal absorption of TCS is limited when the skin barrier is intact, but systemic effects can be observed in $\mathrm{AD}$ patients treated with potent TCS or those receiving treatment under occlusion, or when the treated skin area is large [16].

Treatment with potent or very potent TCS is associated with lower birth weight when the total dosage exceeds $300 \mathrm{~g}$ during the entire pregnancy [16]. There is no increased risk of preterm delivery or malformations associated with the use of TCS during pregnancy [17-19].

The resulting exposure of the fetus depends on the steroid used. Non-fluorinated steroids (prednisolone and methylprednisolone) are metabolized in the placenta by the enzyme $11-\beta$-hydroxysteroid dehydrogenase [20]. Fluorinated steroids (betamethasone and dexamethasone) are metabolized at a far lower rate, and fluticasone should not be used at all during pregnancy as it crosses the placental barrier unmetabolized [19]. Possible systemic effects of glucocorticoids are discussed in detail in the sections on "Systemic Treatments".

In conclusion, TCS are considered to be a safe treatment pre-conception and during pregnancy and lactation. Unrestricted breastfeeding is encouraged. Local treatment of the nipples should not be applied immediately prior to breastfeeding but just after. Due to the side effects of decreased dermal elasticity and thus increased risk of stria development, alternative topical treatments on areas that are susceptible to stria formation during pregnancy may be considered. If the treatment dosage reaches levels at which systemic exposure is considered to be a risk factor, a second drug should be considered to supplement the primary drug, as an alternative to increasing the dosage.

\section{Topical Calcineurin Inhibitors}

Topical calcineurin inhibitors reduce the transcription of cytokines in T cells and mast cells in the skin of $\mathrm{AD}$ patients. These topical drugs can be used for long-term treatment and for the treatment of sensitive skin areas, without risk for skin atrophy. The main TCI used for AD treatment are pimecrolimus and tacrolimus. Local side effects, such as a burning and/or stinging sensation at the application site, appear primarily in the initial treatment phase.

To date, no studies on female fertility following exposure to TCI have been published. Several studies have focused on pregnancy outcome in transplant patients who have received high oral doses of tacrolimus preconception, but these have not emphasized complications related to fertility and conceiving [21].

It has been reported that $50-70 \%$ of the systemic levels of tacrolimus pass through the placenta barrier, based on measurements on blood collected from the umbilical cord at birth [22]. However, the absorption of TCI through the skin barrier is very limited when standard doses to treat $\mathrm{AD}$ are used $[23,24]$. There is no systemic accumulation of tacrolimus when the topical treatment is applied daily [25]. TCI are used throughout pregnancies in transplant patients in far higher systemic doses than those used to treat $\mathrm{AD}$, without an increase in the incidence of birth malformations [26, 27]. During lactation, excretion of TCI in the breast milk of women receiving systemic treatment is very limited [28]; thus, exposure of the child to TCI when using a topical treatment can be expected to be even lower. No studies have been conducted to date on lactating women treated with TCI for their AD, and no follow-up studies on babies exposed to TCI have been performed.

In conclusion, TCI are considered to be a safe treatment pre-conception and during pregnancy and lactation. As systemic absorption is negligible, and no tendency of accumulation has been found, unrestricted breastfeeding is encouraged. 


\section{Phosphordiestherase 4 Inhibitor (Crisaborole)}

Crisaborole exerts its anti-inflammatory effect by inhibiting cellular levels of phosphodiesterase (PDE4). The subsequent increase in cyclic adenosine monophosphate levels activates protein kinase $\mathrm{A}$, resulting in a reduction in pro-inflammatory cytokines and a rise in anti-inflammatory cytokines in keratinocytes and immunocytes ( $\mathrm{T}$ cells, monocytes, macrophages, neutrophils, dendritic cells, and eosinophils) [29-31]. To date, no studies on the treatment of women pre-conception or during pregnancy with crisaborole have been published. Crisaborole is absorbed into the systemic circulation at a higher rate in patients with $\mathrm{AD}$, who have a damaged skin barrier, than in healthy persons [32], although absorption is minimal $[33,34]$. There are no studies on the rate of excretion into breast milk or the effect of crisaborole on the breastfeeding baby. Crisaborole is currently not recommended preconception and during pregnancy or in nursing mothers.

\section{UV Light Therapy}

Ultraviolet light has a local immunosuppressive, immunomodulating, and anti-inflammatory effect on the skin barrier. UV radiation is associated with an increased risk of developing skin cancer [35], but no studies have looked at the link between UVA or UVB light therapy and pregnancy-related complications or long-term effects on the fetus. Studies on vitamin D suggest a positive effect of oral supplementation on fertility and pregnancy outcome, but there are no controlled trials on this [36-38]. Pregnant women who have been exposed to high levels of UVB radiation from working in the sun do not have an increased risk of abnormal delivery outcome [39]. UVB radiation is not considered to be teratogenic and can be used to treat pregnant patients with AD. Pregnant women are, however, at increased risk of developing melasma after UV exposure [40]. Coverage of the face during treatment should therefore be considered.

\section{Systemic Treatments}

\section{Corticosteroids}

Corticosteroids have anti-inflammatory and immunosuppressive effects. Systemic treatment with corticosteroids (SCS) may be considered for short-term treatments of patients with AD [41].

Corticosteroids play a role in several aspects of fertility in women, including local regulation of steroidogenesis in the ovary, oocyte maturation, oocyte rupture from the ovary, maintenance of the corpora lutea, and luteal regression [42]. Effects of corticosteroids on fertility itself have, however, not been demonstrated. The comprehensive side effects related to treatment with SCS in the pregnant woman are the same as those in the non-pregnant one. Effects with particular relevance to pregnancy are increased risks for heightened blood pressure, glucose intolerance, and susceptibility to infection [43]; however, no controlled studies on these effects of SCS specifically in pregnant women have been conducted.

There is a specific pattern to the changes in cortisol levels throughout pregnancy. Maternal endocrine production of cortisol increases towards term at which time the cortisol levels are two- to four-fold higher than pre-gestational levels [44]. Additionally, the placental inactivation of maternal cortisol, regulated by $11-\beta$ hydroxysteroid dehydrogenase, is downregulated to increase fetal exposure and secure organ maturation prior to birth [45]. This physiological process of maturation, however, is at the expense of somatic growth. Synthetic glucocorticoids are not similarly inactivated when passing through the placental barrier and consequently affect the fetus in an unrestrained manner [22, 46].

Overall, steroids are not considered to be teratogenic, but fetal exposure to steroid treatment (median $20 \mathrm{mg} /$ day) during intrauterine development is linked to growth retardation [47]. Women in whom glucocorticoids are insufficiently inactivated when passing through the placental barrier, thereby exposing the fetus to relatively higher levels of these hormones, give birth to smaller children [48]. Single treatments of medium to high doses of synthetic steroids in the third trimester have been shown 
not to affect body size, blood lipids, blood pressure, plasma cortisol, prevalence of diabetes, or history of cardiovascular disease, when the child is followed up at 30 years of age [49]. There is some evidence that the children of mothers treated with steroids during their first trimester have an increased risk for palate cleft $[50,51]$; however, this finding was not supported by several extensive cohort studies [52-54]. It has also been argued that exposure to glucocorticoids during intrauterine development could-theoretically-affect brain development [55]. One study reported that exposure to elevated cortisol levels in the third trimester has a positive effect on the cognitive development of the child [56].

The latest consensus-based European recommendations for patients suffering from $\mathrm{AD}$ recommend that the use of systemic glucocorticoids be restricted to treatments of short duration and that the daily dose should not exceed $0.5 \mathrm{mg} / \mathrm{kg}$ body weight [4]. The same position is held by the European Task Force on Atopic Dermatitis (ETFAD) for pregnant women [57].

In conclusion, systemic glucocorticoids should be restricted to the lowest effective dose and are not recommended for long-term treatment in patients with AD. Supplements of calcium and vitamin $\mathrm{D}$ should be provided to minimize the risk of osteopenia. Treatments with prednisolone, prednisone, or methylprednisolone are preferable as these are metabolized in the placenta at a higher rate than betamethasone and dexamethasone. Unrestricted breastfeeding is encouraged. Concentrations of steroid in breast milk have been shown to be $5-25 \%$ of circulating levels. The dose ingested by the baby would therefore be $0.1 \%$ of the therapeutic dose taken by the mother [58].

\section{Systemic Calcineurin Inhibitors}

Cyclosporine A (CsA) is an immunosuppressive macrolide that inhibits calcineurin and thereby antigen-mediated lymphocyte activation. The result is a decrease in T-cell production of proinflammatory cytokines. CsA is licensed for use in adults with severe $\mathrm{AD}$ in many countries and is an effective agent for the treatment of both pruritus and eczema. Renal impairment is a known risk and may be irreversible.

To date, there have been no studies that have focused on the effect of CsA on female fertility. The fetus can be exposed to high levels of CsA as $64 \%$ of the maternal dosage passes through the placenta to the fetus $[59,60]$. CsA has not unambiguously been shown to promote pregnancy complications or fetal malformations in studies in transplant patients, nor has an increased risk of fetal death relative to the background population been observed [61-64]. However, prematurity and low birth weight are risks associated with CsA treatment [65]. CsA is excreted into breast milk [66], but all published discussions of cases, with one exception, indicate that breastfeeding is safe and that the amount ingested by the infant has no adverse effects [21, 67]. It must be noted that there is very little knowledge on this subject and that there is little clinical experience of the longterm effect of CsA on children exposed to this agent through breastfeeding. It remains relevant that if a systemic drug is warranted, CsA is the drug of choice [57]. Overall, it is accepted that CsA can be used pre-conception and during pregnancy and breastfeeding (Tables 1 and 2). If treatment with CsA is initiated, maternal blood pressure and kidney function should be monitored and testing of CsA blood levels in the child can be considered [68].

\section{Azathioprine}

Azathioprine (AZA) is a prodrug that yields 6-mercaptopurine (6-MP) after being metabolized by thiopurine-S-methyl tranferase. The active drug metabolites produced following subsequent metabolism of 6-MP may be incorporated into replicating DNA and RNA, thereby inhibiting cell division [69].

AZA is cytotoxic in large doses, but at the doses used to treat AD the effect is anti-inflammatory and primarily exerted on rapidly dividing cells, such as T cells [70], in patients with AD. Exposure to AZA is known to moderately increase the risk for nonmelanoma skin cancer [71]. AZA is most commonly used to treat inflammatory bowel disease (IBD) and other autoimmune diseases, but it is used off label as 
an immunosuppressant to treat ADA in many countries [73, 73].

The drug has not been shown to affect fertility in women who have recevied transplants or have autoimmune disease [74], but the literature is very sparse. The placenta is considered to be a relatively good barrier to 6-MP, but the fetus is still exposed to this drug to some extent [75]. AZA is used to treat pregnant women with inflammatory diseases other than $\mathrm{AD}$ and is considered to be a treatment option for pregnant women with severe AD [57]. Maternal blood levels of 6-MP peak $2 \mathrm{~h}$ after ingestion, and most excretion into breast milk takes place within $4 \mathrm{~h}$ of ingestion by the mother [76]. Maternal intake does not lead to immunosuppression in nursing children [77], and the rate of infection and hospitalization is not higher in children exposed to AZA in utero and through breastmilk, when followed up at 3 years of age [78]. The World Health Organization advises against breastfeeding when the mother is being treated with AZA on the basis that potential side effects in the child overweigh the benefits of treatment [79].

In conclusion, AZA is not contraindicated pre-conception and during pregnancy and breastfeeding $[73,80]$, but it is emphasized that the long-term effect of exposure to AZA on the fetus or breastfed child is, at present, not sufficiently investigated $[65,78]$.

\section{Methotrexate}

Methotrexate (MTX) is an immune modulator that exceeds its own intrinsic anti-inflammatory effect by inducing the release of adenosine, a potent anti-inflammatory mediator, from lymphocytes. The drug is also cytostatic in that it inhibits DNA synthesis by lowering the availability of folic acid [81]. MTX is used off label to treat severe $\mathrm{AD}$ in non-pregnant patients, in cases where other drugs have proven ineffective.

MTX does not decrease the chances of conceiving [82]. However, the drug is teratogenic and is contraindicated in pregnancy. A clear pattern of malformations has been identified through evaluations of pregnant women exposed to MTX [82-84]. Although less than $10 \%$ of MTX consumed is excreted into breast milk [85], these small amounts can result in immunosuppression of the infant [82]; therefore, nursing is not recommended for mothers being treated with MTX $[57,86]$.

In conclusion, MTX is contraindicated preconception and during pregnancy and breastfeeding. The possible effect on the nursing child is only speculative at the present time [87].

A 3- to 6-month washout period is recommended before anti-conceptive measures are stopped [57, 73, 88]. The male partner should equally plan a 3-month washout prior to the planned conception. Treatment should be terminated immediately when an unexpected pregnancy occurs. Close monitoring of fetal development, including ultra-sound, is indicated [89].

\section{Mycophenolate mofetil}

Mycophenolate mofetil (MMF) is a cytostatic immunosuppressant that inhibits inosine monophosphate dehydrogenase, the rate-limiting enzyme in the de novo synthesis of guanosine nucleotides. The proliferation of $\mathrm{T}$ and $\mathrm{B}$ lymphocytes is more dependent on this pathway than is the proliferation of other cell types. Therefore, MMF has a more potent cytostatic effect on lymphocytes than on other cell types [90]. At present, no studies on female fertility after exposure to MMF are available, but the drug is teratogenic and associated with a high rate of miscarriages $[61,91]$. It is also associated with a pattern of comprehensive malformations (MMF embryopathy), including ear, mouth, fingers, eyes, and cognitive malfunction $[92,93]$. No study has been conducted on the consequences of breastfeeding while being treated with MMF.

In conclusion, MMF is contraindicated preconception and during pregnancy and breastfeeding. A wash-out period of 3 months must be implemented prior to conception.

\section{Dupilumab}

Dupilumab is a recombinant monoclonal immunoglobulin G4 (IgG4) antibody which blocks the interleukin- 4 receptor subunit alpha (IL-4 R $\alpha$ ); the latter subunit is part of the IL-13 receptor and thus by blocking IL-4 $R \alpha$, 
dupilumab blocks the effects of IL-4 and IL-13, both known mediators of AD [94]. The drug is an effective treatment for $\mathrm{AD}$ and is used in severe refractory cases. Conjunctivitis is an $\mathrm{AD}$ specific side effect [95] of the drug. Results from a recent meta-analysis indicate that dupilumab and cyclosporine are more effective treatments of AD than MTX and AZA [96]. There are no studies to date on fertility, pregnancy complications, embryotoxicity, or consequences of breastfeeding. One case report has been published on the treatment of AD with dupilumab during the whole pregnancy and breastfeeding period, with no complications reported [97]. Thus, current experience is anecdotal. Intrauterine exposure is highly likely. In midgestation, the placenta develops transport systems for immunoglobulins, with the result that IgG4 is transported over the placental barrier at a high rate [98].

In conclusion, there is currently little knowledge available on the possible complications of exposure to dupilumab during pregnancy and the consequences of exposure for the fetus. Dupilumab is currently not recommended pre-conception and during pregnancy or breastfeeding.

\section{CONCLUSION}

As in any patient with $\mathrm{AD}$, the choice of therapeutic strategy for the pregnant or lactating patient depends on multiple factors, such as psycho-social and economic factors, compliance, therapeutic choices, and disease severity, the reported effect on quality of life, concerns for the effect on the unborn child, and many more. Consideration of these factors can result in total control of $\mathrm{AD}$ not always being achieved. It is important to seek sufficient treatment for the patient and reflect on the possible treatments available. It is always the treating doctor's responsibility to stay updated on the effect and side effects of currently available drugs.

$\mathrm{AD}$ activity in pregnancy is unpredictable. It is therefore relevant to evaluate $\mathrm{AD}$ status throughout the pregnancy and adjust the treatment in a timely and appropriate manner.
Systemic treatment can be considered in patients for whom topical treatment and UV light therapy are not adequate. The use of systemic treatment is a specialist task and referral to a specialist should be considered.

The literature on the treatment of $\mathrm{AD}$ during pregnancy and breastfeeding is sparse, especially regarding the new biological treatments. Since interventional studies are not possible in this patient group, we emphasize the importance of specialists publishing any cases which become available.

Initialization of off-label therapy to be conducted taking into account the benefits for the mother versus the costs in terms of long-term side effects and exposure of the fetus or the breastfeeding child. The patient must be well informed about what is known about the treatment and, importantly, what is not yet known, before the intervention. Systemic treatments are widely used to achieve immunosuppression in patients who have undergone transplantation and in those with rheumatic disease and autoimmune disease where the costs of not providing treatment are high if not life threatening for the mother. In $\mathrm{AD}$, it is easier to choose not to treat as it is not a matter of life and death. This, however, is not a legitimate reason for the treating physician to assume a passive role.

\section{ACKNOWLEDGEMENTS}

Funding. No funding or sponsorship was received for this study or publication of this article.

Authorship. All named authors meet the International Committee of Medical Journal Editors (ICMJE) criteria for authorship for this article, take responsibility for the integrity of the work as a whole, and have given their approval for this version to be published.

Disclosures. Sofine Heilskov and Christian Vestergaard have nothing to disclose. Mette $S$ Deleuran is an investigator, speaker and/or advisor for AbbVie, Eli Lilly, Pfizer, Pierre Fabre, 
Leo Pharma, Almirall, Sanofi-Genzyme, and Regeneron. C Vestergaard is an investigator, speaker and/or advisor for Leo Pharma, Novartis, Sanofi-Genzyme, Abb Vie, Eli Lily, and Pierre Fabre. Mette S Deleuran is also a member of the journal's Editorial Board.

Compliance with Ethics Guidelines. This article is based on previously conducted studies and does not contain any studies with human participants or animals performed by any of the authors.

Open Access. This article is licensed under a Creative Commons Attribution-NonCommercial 4.0 International License, which permits any non-commercial use, sharing, adaptation, distribution and reproduction in any medium or format, as long as you give appropriate credit to the original author(s) and the source, provide a link to the Creative Commons licence, and indicate if changes were made. The images or other third party material in this article are included in the article's Creative Commons licence, unless indicated otherwise in a credit line to the material. If material is not included in the article's Creative Commons licence and your intended use is not permitted by statutory regulation or exceeds the permitted use, you will need to obtain permission directly from the copyright holder. To view a copy of this licence, visit http://creativecommons.org/licenses/by$\mathrm{nc} / 4.0 /$.

\section{REFERENCES}

1. Yew YW, Thyssen JP, Silverberg JI. A systematic review and meta-analysis of the regional and agerelated differences in atopic dermatitis clinical characteristics. J Am Acad Dermatol. 2019;80(2): 390-401.

2. Deleuran M, Vestergaard C. Clinical heterogeneity and differential diagnosis of atopic dermatitis. Br J Dermatol. 2014;170(Suppl 1):2-6.

3. Silverberg JI. Atopic dermatitis in adults. Med Clin North Am. 2020;104(1):157-76.

4. Wollenberg A, Barbarot S, Bieber T, Christen-Zaech S, Deleuran M, Fink-Wagner A, et al. Consensus- based European guidelines for treatment of atopic eczema (atopic dermatitis) in adults and children: part II. J Eur Acad Dermatol Venereol. 2018;32(6): 850-78.

5. Barbarot S, Auziere S, Gadkari A, Girolomoni G, Puig L, Simpson EL, et al. Epidemiology of atopic dermatitis in adults: results from an international survey. Allergy. 2018;73(6):1284-93.

6. Guyatt GH, Oxman AD, Vist GE, Kunz R, FalckYtter Y, Alonso-Coello P, et al. GRADE: an emerging consensus on rating quality of evidence and strength of recommendations. BMJ. 2008;336 (7650):924-6.

7. Wilder RL. Hormones, pregnancy, and autoimmune diseases. Ann N Y Acad Sci. 1998;840:45-50.

8. Koutroulis I, Papoutsis J, Kroumpouzos G. Atopic dermatitis in pregnancy: current status and challenges. Obstet Gynecol Surv. 2011;66(10):654-63.

9. Hamann CR, Egeberg A, Wollenberg A, Gislason G, Skov L, Thyssen JP. Pregnancy complications, treatment characteristics and birth outcomes in women with atopic dermatitis in Denmark. J Eur Acad Dermatol Venereol. 2019;33(3):577-87.

10. Capucci S, Hahn-Pedersen J, Vilsbøll A, Kragh N. Systematic reviews of the impact of atopic dermatitis and chronic hand eczema on quality of life compared with other chronic diseases. Dermatitis. 2020. https://doi.org/10.1097/DER.000000000000 0598.

11. Patel KR, Immaneni S, Singam V, Rastogi S, Silverberg JI. Association between atopic dermatitis, depression, and suicidal ideation: a systematic review and meta-analysis. J Am Acad Dermatol. 2019;80(2):402-10.

12. Lundy BL, Jones NA, Field T, Nearing G, Davalos M, Pietro PA, et al. Prenatal depression effects on neonates. Infant Behav Dev. 1999;22(1):119-29.

13. Littleton HL, Bye K, Buck K, Amacker A. Psychosocial stress during pregnancy and perinatal outcomes: a meta-analytic review. J Psychosom Obstet Gynaecol. 2010;31(4):219-28.

14. van den Bergh BR, Mennes M, Stevens V, van der Meere J, Börger N, Stiers P, et al. ADHD deficit as measured in adolescent boys with a continuous performance task is related to antenatal maternal anxiety. Pediatr Res. 2006;59(1):78-82.

15. Davis EP, Sandman CA. The timing of prenatal exposure to maternal cortisol and psychosocial stress is associated with human infant cognitive development. Child Dev. 2010;81(1):131-48. 
16. Chi CC, Wang SH, Mayon-White R, Wojnarowska F. Pregnancy outcomes after maternal exposure to topical corticosteroids: a UK population-based cohort study. JAMA Dermatol. 2013;149(11): 1274-80.

17. Hviid A, Molgaard-Nielsen D. Corticosteroid use during pregnancy and risk of orofacial clefts. CMAJ. 2011;183(7):796-804.

18. Mygind $\mathrm{H}$, Thulstrup AM, Pedersen L, Larsen $\mathrm{H}$. Risk of intrauterine growth retardation, malformations and other birth outcomes in children after topical use of corticosteroid in pregnancy. Acta Obstet Gynecol Scand. 2002;81(3):234-9.

19. Chi CC, Wang SH, Wojnarowska F, Kirtschig G, Davies E, Bennett C. Safety of topical corticosteroids in pregnancy. Cochrane Database Syst Rev. 2015;(10):CD007346.

20. Benediktsson R, Calder AA, Edwards CR, Seckl JR. Placental 11 beta-hydroxysteroid dehydrogenase: a key regulator of fetal glucocorticoid exposure. Clin Endocrinol (Oxf). 1997;46(2):161-6.

21. Grimer M. The CARI guidelines. Calcineurin inhibitors in renal transplantation: pregnancy, lactation and calcineurin inhibitors. Nephrology (Carlton). 2007;12(Suppl 1):S98-105.

22. Colla L, Diena D, Rossetti M, Manzione AM, Marozio L, Benedetto C, et al. Immunosuppression in pregnant women with renal disease: review of the latest evidence in the biologics era. J Nephrol. 2018;31(3):361-83.

23. Reitamo S, Wollenberg A, Schopf E, Perrot JL, Marks $\mathrm{R}$, Ruzicka T, et al. Safety and efficacy of 1 year of tacrolimus ointment monotherapy in adults with atopic dermatitis. The European Tacrolimus Ointment Study Group. Arch Dermatol. 2000;136(8): 999-1006.

24. Undre NA, Moloney FJ, Ahmadi S, Stevenson P, Murphy GM. Skin and systemic pharmacokinetics of tacrolimus following topical application of tacrolimus ointment in adults with moderate to severe atopic dermatitis. $\mathrm{Br} \mathrm{J}$ Dermatol. 2009;160(3):665-9.

25. Rubins A, Gutmane R, Valdmane N, Stevenson P, Foster C, Undre N. Pharmacokinetics of $0.1 \%$ tacrolimus ointment after first and repeated application to adults with moderate to severe atopic dermatitis. J Invest Dermatol. 2005;125(1):68-71.

26. Jain AB, Reyes J, Marcos A, Mazariegos G, Eghtesad $\mathrm{B}$, Fontes PA, et al. Pregnancy after liver transplantation with tacrolimus immunosuppression: a single center's experience update at 13 years. Transplantation. 2003;76(5):827-32.
27. Kainz A, Harabacz I, Cowlrick IS, Gadgil SD, Hagiwara D. Review of the course and outcome of 100 pregnancies in 84 women treated with tacrolimus. Transplantation. 2000;70(12):1718-21.

28. Hiramatsu Y, Yoshida S, Kotani T, Nakamura E, Kimura Y, Fujita D, et al. Changes in the blood level, efficacy, and safety of tacrolimus in pregnancy and the lactation period in patients with systemic lupus erythematosus. Lupus. 2018;27(14): 2245-52.

29. Maurice DH, Ke H, Ahmad F, Wang Y, Chung J, Manganiello VC. Advances in targeting cyclic nucleotide phosphodiesterases. Nat Rev Drug Discov. 2014;13(4):290-314.

30. Sakkas LI, Mavropoulos A, Bogdanos DP. Phosphodiesterase 4 inhibitors in immune-mediated diseases: mode of action, clinical applications, current and future perspectives. Curr Med Chem. 2017;24(28):3054-67.

31. Li H, Zuo J, Tang W. Phosphodiesterase-4 inhibitors for the treatment of inflammatory diseases. Front Pharmacol. 2018;9:1048.

32. Purohit V, Riley S, Tan H, Ports WC. Predictors of systemic exposure to topical crisaborole: a nonlinear regression analysis. J Clin Pharmacol. 2020;60(10):1344-54. https://doi.org/10.1002/jcph. 1624.

33. Zane LT, Kircik L, Call R, Tschen E, Draelos ZD, Chanda S, et al. Crisaborole topical ointment, 2\% in patients ages 2 to 17 years with atopic dermatitis: a phase 1b, open-label, maximal-use systemic exposure study. Pediatr Dermatol. 2016;33(4): 380-7.

34. Tom WL, Van Syoc M, Chanda S, Zane LT. Pharmacokinetic profile, safety, and tolerability of crisaborole topical ointment, $2 \%$ in adolescents with atopic dermatitis: an open-label phase 2 a study. Pediatr Dermatol. 2016;33(2):150-9.

35. Patrizi A, Raone B, Ravaioli GM. Management of atopic dermatitis: safety and efficacy of phototherapy. Clin Cosmet Investig Dermatol. 2015;8: 511-20.

36. Jensen A, Nielsen ML, Guleria S, Kjaer SK, Heitmann BL, Kesmodel US. Chances of live birth after exposure to vitamin D-fortified margarine in women with fertility problems: results from a Danish population-based cohort study. Fertil Steril. 2019;113(2):383-91.

37. Lerchbaum E, Rabe T. Vitamin D and female fertility. Curr Opin Obstet Gynecol. 2014;26(3):145-50. 
38. Pilz S, Zittermann A, Obeid R, Hahn A, Pludowski P, Trummer $C$, et al. The role of vitamin $D$ in fertility and during pregnancy and lactation: a review of clinical data. Int J Environ Res Public Health. 2018;15(10):2241. https://doi.org/10.3390/ ijerph15102241.

39. El-Saie LT, Rabie AR, Kamel MI, Seddeik AK, Elsaie ML. Effect of narrowband ultraviolet B phototherapy on serum folic acid levels in patients with psoriasis. Lasers Med Sci. 2011;26(4):481-5.

40. Ortonne JP, Arellano I, Berneburg M, Cestari T, Chan H, Grimes P, et al. A global survey of the role of ultraviolet radiation and hormonal influences in the development of melasma. J Eur Acad Dermatol Venereol. 2009;23(11):1254-62.

41. Drucker AM, Eyerich K, de Bruin-Weller MS, Thyssen JP, Spuls PI, Irvine AD, et al. Use of systemic corticosteroids for atopic dermatitis: International Eczema Council consensus statement. Br J Dermatol. $2018 ; 178(3): 768-75$.

42. Whirledge S, Cidlowski JA. Glucocorticoids, stress, and fertility. Minerva Endocrinol. 2010;35(2): 109-25.

43. Jain V, Gordon C. Managing pregnancy in inflammatory rheumatological diseases. Arthritis Res Ther. 2011;13(1):206.

44. Mastorakos G, Ilias I. Maternal and fetal hypothalamic-pituitary-adrenal axes during pregnancy and postpartum. Ann N Y Acad Sci. 2003;997:136-49.

45. Togher KL, Togher KL, O'Keeffe MM, Khashan AS, et al. Epigenetic regulation of the placental HSD11B2 barrier and its role as a critical regulator of fetal development. Epigenetics. 2014;9(6): 816-22.

46. Murphy VE, Fittock RJ, Zarzycki PK, Delahunty MM, Smith R, Clifton VL. Metabolism of synthetic steroids by the human placenta. Placenta. 2007;28(1):39-46.

47. Gur C, Diav-Citrin O, Shechtman S, Arnon J, Ornoy A. Pregnancy outcome after first trimester exposure to corticosteroids: a prospective controlled study. Reprod Toxicol. 2004;18(1):93-101.

48. McTernan CL, Draper N, Nicholson H, Chalder SM, Driver P, Hewison M, et al. Reduced placental 11beta-hydroxysteroid dehydrogenase type 2 mRNA levels in human pregnancies complicated by intrauterine growth restriction: an analysis of possible mechanisms. J Clin Endocrinol Metab. 2001;86(10):4979-83.

49. Dalziel SR, Walker NK, Parag V, Mantell C, Rea HH, Rodgers A, et al. Cardiovascular risk factors after antenatal exposure to betamethasone: 30-year follow-up of a randomised controlled trial. Lancet. 2005;365(9474):1856-62.

50. Park-Wyllie L, Mazzotta P, Pastuszak A, Moretti ME, Beique L, Hunnisett L, et al. Birth defects after maternal exposure to corticosteroids: prospective cohort study and meta-analysis of epidemiological studies. Teratology. 2000;62(6):385-92.

51. Edwards MJ, Agho K, Attia J, Diaz P, Hayes T, Illingworth A, et al. Case-control study of cleft lip or palate after maternal use of topical corticosteroids during pregnancy. Am J Med Genet A. 2003;120A(4):459-63.

52. Bay Bjorn AM, Ehrenstein V, Hundborg HH, Nohr EA, Sorensen HT, Norgaard M. Use of corticosteroids in early pregnancy is not associated with risk of oral clefts and other congenital malformations in offspring. Am J Ther. 2014;21(2):73-80.

53. Czeizel AE, Rockenbauer M. Population-based casecontrol study of teratogenic potential of corticosteroids. Teratology. 1997;56(5):335-40.

54. Källén B. Maternal drug use and infant cleft lip/palate with special reference to corticoids. Cleft Palate Craniofac J. 2003;40(6):624-8.

55. Ding YX, Cui H. The brain development of infants with intrauterine growth restriction: role of glucocorticoids. Horm Mol Biol Clin Investig. 2019;39(1). https://doi.org/10.1515/hmbci-2019-0016.

56. Davis EP, Head K, Buss C, Sandman CA. Prenatal maternal cortisol concentrations predict neurodevelopment in middle childhood. Psychoneuroendocrinology. 2017;75:56-63.

57. Vestergaard C, Wollenberg A, Barbarot S, ChristenZaech S, Deleuran M, Spuls P, et al. European task force on atopic dermatitis position paper: treatment of parental atopic dermatitis during preconception, pregnancy and lactation period. J Eur Acad Dermatol Venereol. 2019;33(9):1644-59.

58. Ost L, Wettrell G, Björkhem I, Rane A. Prednisolone excretion in human milk. J Pediatr. 1985;106(6): 1008-11.

59. Amor KT, Ryan C, Menter A. The use of cyclosporine in dermatology: part I. J Am Acad Dermatol. 2010;63(6):925-46 (quiz 947-8).

60. Ryan C, Amor KT, Menter A. The use of cyclosporine in dermatology: part II. J Am Acad Dermatol. 2010;63(6):949-72 (quiz 973-4).

61. Mohamed-Ahmed O, Nelson-Piercy C, Bramham K, Gao H, Kurinczuk JJ, Brocklehurst P, et al. Pregnancy outcomes in liver and cardiothoracic 
transplant recipients: a UK national cohort study. PLoS One. 2014;9(2):e89151.

62. Perales-Puchalt A, Vila Vives JM, Lopez Montes J, Diago Almela VJ, Perales A. Pregnancy outcomes after kidney transplantation-immunosuppressive therapy comparison. J Matern Fetal Neonatal Med. 2012;25(8):1363-6.

63. Nulman I, Sgro M, Barrera M, Chitayat D, Cairney J, Koren G. Long-term neurodevelopment of children exposed in utero to ciclosporin after maternal renal transplant. Paediatr Drugs. 2010;12(2):113-22.

64. Bar Oz B, Hackman R, Einarson T, Koren G. Pregnancy outcome after cyclosporine therapy during pregnancy: a meta-analysis. Transplantation. 2001;71(8):1051-5.

65. Prévot A, Martini S, Guignard JP. In utero exposure to immunosuppressive drugs. Biol Neonate. 2002;81(2):73-81.

66. Moretti ME, Sgro M, Johnson DW, Sauve RS, Woolgar MJ, Taddio A, et al. Cyclosporine excretion into breast milk. Transplantation. 2003;75(12): 2144-6.

67. Morton A. Cyclosporine and lactation. Nephrology (Carlton). 2011;16(2):249.

68. Cochat P, Decramer S, Robert-Gnansia E, Dubourg L, Audra P. Renal outcome of children exposed to cyclosporine in utero. Transplant Proc. 2004;36(2 Suppl):208S-10S.

69. Nielsen $\mathrm{OH}$, Bjerrum JT, Herfarth $\mathrm{H}$, Rogler G. Recent advances using immunomodulators for inflammatory bowel disease. J Clin Pharmacol. 2013;53(6):575-88.

70. Polifka JE, Friedman JM. Teratogen update: azathioprine and 6-mercaptopurine. Teratology. 2002;65(5):240-61.

71. Hagen JW, Pugliano-Mauro MA. Nonmelanoma skin cancer risk in patients with inflammatory bowel disease undergoing thiopurine therapy: a systematic review of the literature. Dermatol Surg. 2018;44(4):469-80.

72. Restellini S, Biedermann L, Hruz P, Mottet C, Moens A, Ferrante $M$, et al. Update on the management of inflammatory bowel disease during pregnancy and breastfeeding. Digestion. 2020;101(1):27-42.

73. Fanouriakis A, Kostopoulou M, Cheema K, Anders HJ, Aringer M, Bajema I, et al. 2019 Update of the Joint European League Against Rheumatism and European Renal Association-European Dialysis and Transplant Association (EULAR/ERA-EDTA) recommendations for the management of lupus nephritis. Ann Rheum Dis. 2020;79(6):713-23.

74. Heetun ZS, Byrnes C, Neary P, O'Morain C. Review article: reproduction in the patient with inflammatory bowel disease. Aliment Pharmacol Ther. 2007;26(4):513-33.

75. Hutson JR, Lubetsky A, Walfisch A, Ballios BG, Garcia-Bournissen F, Koren G. The transfer of 6-mercaptopurine in the dually perfused human placenta. Reprod Toxicol. 2011;32(3):349-53.

76. Christensen LA, Dahlerup JF, Nielsen MJ, Fallingborg JF, Schmiegelow K. Azathioprine treatment during lactation. Aliment Pharmacol Ther. 2008;28(10):1209-13.

77. Sau A, Clarke S, Bass J, Kaiser A, Marinaki A, NelsonPiercy C. Azathioprine and breastfeeding: is it safe? BJOG. 2007;114(4):498-501.

78. Angelberger S, Reinisch W, Messerschmidt A, Miehsler W, Novacek G, Vogelsang H, et al. Longterm follow-up of babies exposed to azathioprine in utero and via breastfeeding. J Crohns Colitis. 2011;5(2):95-100.

79. Meggitt SJ, Anstey AV, Mohd Mustapa MF, Reynolds NJ, Wakelin S. British Association of Dermatologists' guidelines for the safe and effective prescribing of azathioprine 2011. Br J Dermat. 2011;165(4):711-34.

80. Akbari M, Shah S, Velayos FS, Mahadevan U, Cheifetz AS. Systematic review and meta-analysis on the effects of thiopurines on birth outcomes from female and male patients with inflammatory bowel disease. Inflamm Bowel Dis. 2013;19(1): $15-22$.

81. Cronstein B. How does methotrexate suppress inflammation? Clin Exp Rheumatol. 2010;28(5 Suppl 61):S21-23.

82. Lloyd ME, Carr M, McElhatton P, Hall GM, Hughes RA. The effects of methotrexate on pregnancy, fertility and lactation. QJM. 1999;92(10):551-63.

83. MacDonald K, Norman WV, Popescu O. New anomalies due to methotrexate and misoprostol exposure in early pregnancy. Int J Gynaecol Obstet. 2013;122(3):267-8.

84. Verberne EA, de Haan E, van Tintelen JP, Lindhout D, van Haelst MM. Fetal methotrexate syndrome: a systematic review of case reports. Reprod Toxicol. 2019;87:125-39.

85. Thorne JC, Nadarajah $\mathrm{T}$, Moretti $\mathrm{M}$, Ito $\mathrm{S}$. Methotrexate use in a breastfeeding patient with 
rheumatoid arthritis. J Rheumatol. 2014;41(11): 2332.

86. Bermas BL. Lactation and management of postpartum disease. Rheum Dis Clin North Am. 2017;43(2):249-62.

87. Martínez Lopez JA, Loza E, Carmona L. Systematic review on the safety of methotrexate in rheumatoid arthritis regarding the reproductive system (fertility, pregnancy, and breastfeeding). Clin Exp Rheumatol. 2009;27(4):678-84.

88. Gotestam Skorpen C, Hoeltzenbein M, Tincani A, Fischer-Betz R, Elefant E, Chambers C, et al. The EULAR points to consider for use of antirheumatic drugs before pregnancy, and during pregnancy and lactation. Ann Rheum Dis. 2016;75(5):795-810.

89. Weber-Schoendorfer C, Chambers C, Wacker E, Beghin D, Bernard N, Network of French Pharmacovigilance Centers, et al. Pregnancy outcome after methotrexate treatment for rheumatic disease prior to or during early pregnancy: a prospective multicenter cohort study. Arthritis Rheumatol. 2014;66(5):1101-10.

90. Ransom JT. Mechanism of action of mycophenolate mofetil. Ther Drug Monit. 1995;17(6):681-4.

91. Hoeltzenbein M, Elefant E, Vial T, Finkel-Pekarsky V, Stephens S, Clementi M, et al. Teratogenicity of mycophenolate confirmed in a prospective study of the European Network of Teratology Information Services. Am J Med Genet A. 2012;158A(3):588-96.
92. Merlob P, Stahl B, Klinger G. Tetrada of the possible mycophenolate mofetil embryopathy: a review. Reprod Toxicol. 2009;28(1):105-8.

93. Sifontis NM, Coscia LA, Constantinescu S, Lavelanet AF, Moritz MJ, Armenti VT. Pregnancy outcomes in solid organ transplant recipients with exposure to mycophenolate mofetil or sirolimus. Transplantation. 2006;82(12):1698-702.

94. Seegraber M, Srour J, Walter A, Knop M, Wollenberg A. Dupilumab for treatment of atopic dermatitis. Expert Rev Clin Pharmacol. 2018;11(5):467-74.

95. Wernham AGH, Veitch D, Grindlay DJC, Rogers NK, Harman KE. What's new in atopic eczema? An analysis of systematic reviews published in 2017. Part 1: treatment and prevention. Clin Exp Dermatol. 2019;44(8):861-7.

96. Drucker AM, Ellis AG, Bohdanowicz M, Mashayekhi S, Yiu ZZN, Rochwerg B, et al. Systemic immunomodulatory treatments for patients with atopic dermatitis: a systematic review and network meta-analysis. JAMA Dermatol. 2020.

97. Kage P, Simon JC, Treudler R. A case of atopic eczema treated safely with dupilumab during pregnancy and lactation. J Eur Acad Dermatol Venereol. 2020:34(6):e256-7. https://doi.org/10. $1111 /$ jdv.16235.

98. Koren G, Ornoy A. The role of the placenta in drug transport and fetal drug exposure. Expert Rev Clin Pharmacol. 2018;11(4):373-85. 